\title{
On void structure and strength of foamed concrete made without/with additives
}

\author{
Ameer A. Hilal*ab, Nicholas Howard Thoma ${ }^{\text {a }}$, Andrew Robert Dawsona \\ ${ }^{a}$ Department of Civil Engineering, Faculty of Engineering, University of Nottingham, University \\ Park, Nottingham NG7 2RD, UK Tel: +44 (0) 115846 8427, Fax: +44 (0) 1159513909. \\ ${ }^{b}$ Civil Engineering Department, Faculty of Engineering, University of Anbar, Iraq. \\ *Corresponding author, E-mail: evxaah@nottingham.ac.uk,ameer_amn@yahoo.com
}

\begin{abstract}
A study has been undertaken to investigate the effect of different additives on the strength of foamed concrete by characterising air-void size parameters and identifying the influence of these parameters and changes to cement paste microstructure on strength. Nine different mixes, made using a pre-formed foam, were investigated with varying density (nominally 1300, 1600 and $1900 \mathrm{~kg} / \mathrm{m}^{3}$ ) without/with additives (silica fume, fly ash and superplasticizer), used either individually or together. Optical microscopy and scanning electron microscopy were used in this investigation. Compared to the conventional mixes, inclusion of additives (individually or in combination) helped to improve both the cement paste microstructure and air-void structure of foamed concrete. For a given density, although the additives in combination led to increased void numbers, higher strength was achieved due to reduced void size and connectivity, by preventing their merging and producing a narrow void size distribution. Furthermore, adding a superplasticizer on its own resulted in a void structure fairly similar to that from all additives in combination, implying that it is the superplasticizer that has the greatest influence on voids. Not only enhancement of void structure but also improved cement paste microstructure both contribute to the strength of the foamed concrete.
\end{abstract}

Keywords: Foamed concrete, Mineral additives, Superplasticizer, Pore structure, Strength.

\section{Introduction}

In aerated concrete, the structure is affected by the method of pore-formation (gas or foaming) and is characterised into a micro-porous matrix and macropores [1]. Foamed concrete is a particular example of aerated concrete in which addition pores have been 
introduced by the introduction of either preformed foam or by chemical action after mixing. In the study reported here, preformed foam was applied.

Ramamurthy et al. [2] and Nambiar and Ramamurthy [3], mentioned that air-void distribution is one of the most significant micro-properties influencing strength of foamed concrete and Ramamurthy et al. [2] found that foamed concrete with narrower air-void size distribution shows higher strength.

The pore structure of foamed concrete is classified as gel pores, capillary pores and air-voids (air entrained and entrapped pores) [2,4]. In addition, the air-voids in the foamed concrete may be characterized by parameters such as volume, size, shape, size distribution and spacing between air-voids [3]. To investigate this, image analysis software was used on images of specimens captured by using an optical microscope.

Although the compressive strength of porous materials has been expressed as a function of porosity by many researchers, some have mentioned that determination of total air void content (porosity) is not sufficient as shape, size and distribution of voids may affect the strength and durability of foamed concrete [5].

Kearsley [5] investigated the microstructure of foamed concrete produced with the inclusion of either classified (pfa) or unclassified (Pozz-fill) fly ash with nominal densities 1000, 1250 and $1500 \mathrm{~kg} / \mathrm{m}^{3}$. It was found that, at any given density, there was no obvious effect of median void diameter on the compressive strength.

Nambiar and Ramamurthy [3] determined the air void size distribution of foamed concrete mixes with different added foam volumes $(10 \%, 30 \%$ and $50 \%)$ and found that the size of the larger voids increased sharply with an increase in foam volume, while for the same foam volume they were smaller for a cement-fly ash mix compared to a cement-sand mix. In addition, $\mathrm{D}_{90}\left(90^{\text {th }}\right.$ percentile) correlated better with strength than $\mathrm{D}_{50}$ (median pore size) indicating that it was the larger pores that influenced the strength more than the smaller pores. Thus, it is well known that with the same matrix and void volume (porosity), the strength of material containing more large-size voids is lower. This paper aims to investigate, from pore structural and cement paste microstructural points of view, the strength of foamed concretes having the same air void contents, for a given density, but different matrices produced by using different additives (individually and in combination). This will be achieved by:

- Determining and comparing the size distributions of air voids of the foamed concrete mixes without/with different additives.

- Identifying the influence of size parameters on strength.

- Investigating the effect of cement paste improvement on foamed concrete strength. 


\section{Materials, mix proportions and production}

Full details of the materials used, mix proportions and production process can be found in a previous publication [6], but essential information can be summarized as follows:

\subsection{Materials}

To produce conventional foamed concrete, the following constituent materials were used in this study.

- Portland cement, CEM I-52,5 N (3.15 S.G.) conforming to BS EN 197-1:2011 [7].

- Natural sand (2.65 S.G.) conforming to BS 882:1992 [8] with additional sieving to remove particles greater than $2.36 \mathrm{~mm}$.

- Fresh, clean and drinkable water.

- Foam $\left(45 \mathrm{~kg} / \mathrm{m}^{3}\right)$ was produced by blending the foaming agent, EABASSOC (1.05 S.G.), water and compressed air in predetermined proportions (45 $\mathrm{g}$ water to $0.8 \mathrm{ml}$ foaming agent) in a foam generator, STONEFOAM-4.

Then, to improve the cement paste microstructure and the air-void structure, the following additives were used individually or together depending on the desired mixes (see Table 1):

- Silica fume: Elkem Microsilica (2.2 S.G., 92\% $\mathrm{SiO}_{2}$, mean particle size $0.15 \mu \mathrm{m}$ and specific surface $20 \mathrm{~m}^{2} / \mathrm{g}$ ).

- Fly Ash: CEMEX fly ash-class S (2.09 S.G.) conforming to BS EN 405-1:2005 [9].

- Superplasticizer : MIGHTY 21 EG made by Kao Chemical GmbH of density $1.1 \mathrm{~g} / \mathrm{cm}^{3}$, compatible with the EABASSOC foaming agent.

\subsection{Mix proportions}

In this study, nine differently proportioned mixes were designed as follows: conventional mixes FC and modified mixes using all additives together FCa at three nominal densities, 1300 (FC3 and FCa3), 1600 (FC6 and FCa6) and 1900 (FC9 and FCa9) kg/m³; three further mixes at $1600 \mathrm{~kg} / \mathrm{m}^{3}$ with individual additives, silica fume (FCs6), fly ash (FCf6) and superplasticizer (FCp6), see Table (1).

Mix proportioning began with the selection of the target density $\left(1300-1900 \mathrm{~kg} / \mathrm{m}^{3}\right)$, the cement content and the water to cement ratio. The mix was then proportioned by the method of absolute volumes. For each mix the water/binder ratio required to produce a stable mix (fresh density to target density ratio close to unity) was determined by trials while the required foam volume was determined from the mix design. A dosage of superplasticizer ( $1.5 \%$ of binder weight) was adopted for all relevant mixes. Silica fume was added to four of 
the mixes at $10 \%$ of the cement weight (see Table 1). Fly ash replacement was limited to $20 \%$ by weight of sand.

\subsection{Production}

Component materials were added into the mixer in the following sequence: dry materials (including additives, if any), water with dissolved admixture to produce the base mix (mortar) and then foam to produce the foamed concrete. The foamed concrete mix was placed in cube moulds in two approximately equal layers. The sides of the moulds were lightly tapped after placing each layer until the surface of the layer had subsided approximately to level [10]. After levelling the specimens' surfaces, all specimens were covered with thick nylon to prevent evaporation and then removed from moulds within 24 hours. Because sealed-curing reflects typical industry practice for foamed concrete [11], all specimens were sealed-cured (wrapped in cling film) and stored at about $20^{\circ} \mathrm{C}$ until testing.

\section{Experimental details}

\subsection{Strength test}

For both foamed concrete and unfoamed (mortar) mixes, compressive strength testing was carried out on $100 \mathrm{~mm}$ cubes in accordance with BS EN 12390-3:2002 [12] and in each case the results quoted are the average of three specimens.

\subsection{Entrained air-void structure investigation}

For the void size investigation, three slices $(50 \times 50 \times 15 \mathrm{~mm})$ were cut, perpendicular to the cast face, from the centres of three cured foamed concrete specimens. To enhance the contrast between the air voids and the matrix, the specimens were first polished and cleaned to remove any residues and then treated by applying two coats of permanent marker ink to them. Finally, after drying, a white powder (Sodium bicarbonate) with a minimum particle size of 5 $\mu \mathrm{m}$ was pressed into the surfaces of the specimens and forced into the voids leaving the concrete surface with excellent properties for image analysis, namely a black surface and white voids. This technique is described in details in BS EN 480-11 [13] and by Nambiar and Ramamurthy [3].

A camera connected to an optical microscope and a computer was used to capture the images of the foamed concrete mixes. From SEM images of both unfoamed and foamed concrete mixes, it was shown that the smallest entrained air void diameter identified was about $20 \mu \mathrm{m}$ [14], also see Figure (1). Therefore, a microscope magnification of $(23 \times)$ was chosen in order that air voids with diameters in excess of $20 \mu \mathrm{m}$ could be easily identified. With this magnification, a pixel represents $6 \mu \mathrm{m}$ and the image area is $178.52 \mathrm{~mm}^{2}(15.43 \mathrm{~mm} \times$ 
$11.57 \mathrm{~mm})$. Ten images were captured for each mix and then digitized, converted into binary form and analysed using the ImageJ software. For this study, only two phases, air voids and solid, were of interest, Figure (2).

To create the final binary image required for analysis, the threshold value, below which all pixels were considered voids and above which they were considered as solid, was selected from a histogram of grey levels. Although the grey-scale histograms did not have a sharp boundary between the two phases (voids and matrix), there was always a minimum in the boundary region and this was set as the threshold for analysis of the images in this study.

Since there is a sharp contrast between the white air voids and the surrounding black matrix, for this study, it was found that the simple digital operation of hole filling was sufficient, although software operations such as dilation, erosion, opening, closing as well as hole filling have all been suggested by others as being useful in application to concrete microscopy [3].

\subsection{Microstructure investigation}

For microstructure investigation, the specimens were studied through secondary electron SE and backscattered electron BSE images which were captured using a Scanning Electron Microscope $(\mathrm{SEM})$ in the form of $2 \mathrm{D}$-images. For this technique, samples of about $20 \times 20$ $\mathrm{mm}$ size with a minimum thickness of about $12 \mathrm{~mm}$ were cut from the cubic specimens using a diamond cutter. The faces of the specimens were cut perpendicular to the cast face (parallel to the casting direction) [15]. After drying for 2 days at $105^{\circ} \mathrm{C}$ and to ensure the stability of the air void walls during polishing, the cooled specimens were vacuum impregnated with a slow setting epoxy. Then, the impregnated specimens were polished with $240 \#, 400 \#, 800 \#$ and 1200\# silicon carbide abrasive (58.5, 35, 21.8 and 15.3 micron, respectively) using a rotating grinder and then a final stage made use of a 5 micron abrasive (4000\#). In order to avoid distortion of SE and BSE images due to a negative charge which may have built up on the sample surface under the high energy incident electron beam, the samples, nonconductive materials, were coated with a thin film of conductive material, carbon for BSE mode and gold for SE mode, before investigating with the SEM. 


\section{Results and discussion}

\subsection{Effect of additives on air-void structure}

For each void, an effective diameter was calculated by measuring the void area and assuming it to be perfect circle [5]. Figure (3) shows the resulting pore size distributions for FC and FCa foamed concrete mixes with densities of 1300,1600 and $1900 \mathrm{~kg} / \mathrm{m}^{3}$. From the results, sizes vary between approximately 20 and $2000 \mu \mathrm{m}$. It is clear that at higher density (less added foam), the proportion of the larger voids decreases leading to a narrower air void size distribution. In addition, for a given density, the additives in combination led to increased void numbers by preventing their merging, see Figure (2), and producing a narrower void size distribution compared to a corresponding conventional mix. To investigate the effect of additives, individually and in combination, on void structure, Figure (4) shows the void size distributions of $1600 \mathrm{~kg} / \mathrm{m}^{3}$ mixes.

In order to quantify and compare the air void distribution of selected mixes, the parameters $\mathrm{D}_{50}$ and $\mathrm{D}_{90}$ were calculated on the basis of number of voids, see Table (2). It can be seen that both $\mathrm{D}_{50}$ and $\mathrm{D}_{90}$ increased with foam volume while they decreased significantly with additives in combination (FCa mixes) suggesting that the inclusion of these additives helps in achieving more uniform distribution of air voids (less merging) than for the FC mixes. Compared to FC6, using the additives individually slightly deceased D50, while D90 was significantly decreased, again implying that additives helped in reducing the merging of voids and so reduced the areas of the larger voids. This is also clear from the SEM images of the $1600 \mathrm{~kg} / \mathrm{m}^{3}$ mixes shown in Figure (5). It can also be seen from Figures 2 and 5 that adding a superplasticizer on its own resulted in a void structure fairly similar to that when using all the additives in combination, implying that it is the superplasticizer that has the greatest influence on void sizes and size distribution.

\subsection{Effect of void structure characterisation on strength}

Foamed concrete is a porous material; therefore its pore structure plays a dominant role in controlling its properties. Figure (6) shows the effect of void size distribution parameters on the 28-day compressive strength of FC and FCa mixes, while Figure (7) illustrates the effect for the $1600 \mathrm{~kg} / \mathrm{m}^{3}$ mixes. It can be seen that for all mixes, a higher foam volume (nominally $1300 \mathrm{~kg} / \mathrm{m}^{3}$ ) resulted in a greater degree of void merging, leading to large irregular voids which resulted in a wide distribution of void sizes and lower strength. In addition, a reduction in D50 and D90 is clearly linked to an increase in strength for each density implying that the effect of additives (both individually and in combination) was significant. However, it is 
known that changes to the cement paste microstructure due to additives, Figures (8) and (9), will also contribute to strength gain. Therefore for a given density, the questions are these; does this strength improvement come from the enhancement of void structure or the paste microstructure improvement due to additives and to what extent does each affect the strength?

\subsection{Effect of microstructural changes on strength}

To answer the above questions, the compressive strengths of unfoamed mixes were investigated and compared to those of foamed concrete, see Figure (10). It is evident that the compressive strengths of the most dense unfoamed mixes (FC9 and FCa9) are higher than unfoamed FC3 and FCa3 mixes. The reason is the higher aggregate/binder ratio $(\mathrm{a} / \mathrm{b})$ in the FC9 and FCa9 which may lead to reduced damage in the interfacial transition zone (ITZ) between the aggregate and cement paste by reducing shrinkage and bleeding. In addition, with high $\mathrm{a} / \mathrm{b}$ ratio the cement paste would be less, resulting in, on the one hand, reduced thermal changes from hydration of cement and, on the other hand, a smaller voids fraction and so less adverse effect on strength [16]. In addition, some water may be absorbed by a larger amount of aggregate in FC9 and FCa9 leading to reduce the effective w/b ratio. Neville [16] also stated that strength of a mix decreases as the proportion of aggregate increases from 0 to $20 \%$ but it increases for aggregate proportions from $40 \%$ to $80 \%$. He added that the same behavior was noticed at different $\mathrm{w} / \mathrm{c}$ ratios but the reason for this pattern of behavior is not clear.

Similar strength increases is seen in the foamed concrete mixes FC9 and FCa9 being stronger than the comparable $\mathrm{FC} 3 / 6$ and $\mathrm{FCa} 3 / \mathrm{a} 6$ mixes, although the rate of strength increases with density appears somewhat greater for foamed version compared to unfoamed version.

It can be seen from Figure (10) that inclusion of additives (individually or in combination) helps to improve the strength of both unfoamed and foamed mixes. This is due to the additional reduction in porosity of cement paste and an improved interface between it and the aggregate by:

- A substantial reduction in the mixing water (using a superplastisizer);

- Forming calcium silicate hydrate (C-S-H) from a pozzolanic reaction of fly ash with the lime produced from the hydration of cement and water;

- Acting as fine filler (silica fume).

See Figure (8). This was noticed, firstly, from the difference between the vacuum saturation porosity (entrained air voids and capillary voids) and the entrained ( $>20 \mu \mathrm{m})$ void content calculated from analysis of optical microscopy images. It was found that the capillary 
porosity of FCa is less than that of FC at all investigated densities. Secondly, micro-hardness values of the ITZ at $30 \mu \mathrm{m}$ distance from the aggregate surface (five readings averaged from a Vickers micro-hardness test, square base pyramid indenter, with test load $10 \mathrm{~g}$ and contact time 15s) were 39.66, 59.3 and $91.13 \mathrm{HV}$ for FC3, FC6 and FC9 respectively while for FCa3, FCa6 and FCa9 they were 54.83, 85.56 and 111.43 , respectively (1 $\mathrm{HV}=1$ $\left.\mathrm{kgf} / \mathrm{cm}^{3}=0.09806650 \mathrm{MPa}\right)$.

\subsection{General discussion}

The compressive strength reduction from unfoamed and foamed concrete for each mix is shown in Figure (11). It can be seen that this reduction decreases with increase in density for both FC and FCa mixes. For the same density, the reduction was lower in the case of FCa indicating that the void structure improvement helped in increasing the strength. This is also evident from the results for individual additives (silica fume, fly ash and superplastisizer) at the same density $\left(1600 \mathrm{~kg} / \mathrm{m}^{3}\right)$.

A similar interpretation can be made from Figure (12) which illustrates the reduction for both unfoamed and foamed concretes between a mix with additives (individual or in combination) and a conventional mix. The difference between values of unfoamed and foamed concrete reductions implies that not only the enhancement of cement paste microstructure but also improvements in the void structure of foamed concrete both will contribute to strength gain. In addition, the effect of each variable, i.e. mortar strength (changes to cement paste microstructure) and void size parameters ( $D_{50}$ and $D_{90}$ ), were examined from a statistical point of view using the Chi Squared Test which is the sum of the squared difference between observed and expected data divided by the expected data. With a degree of freedom equal to 8 (the number of all categories minus 1) and a probability value $\alpha=0.1$ (which means that there is a $10 \%$ probability that any deviation from expected results is due to change), the value of $\chi^{2}$ equals 13.362. It was found that the greatest effect was for $\mathrm{D}_{90}$ (with a power relation with compressive strength, $\chi^{2}=6.535$ ) followed by mortar strength (with a linear relation with foamed concrete strength, $\chi^{2}=10.101$ ). Meanwhile, with a power relationship, $\chi^{2}=16.841$, D50 does not have any significant effect on the strength of the investigated foamed concrete. These relationships are shown in Figure (13) which demonstrates that $\mathrm{D}_{90}$ correlates better than D50 with strength of foamed concrete implying that it is the larger pores that influence the strength. Similar behavior was noticed by Nambiar and Ramamurthy [3]. 


\section{Conclusions}

Based on the results and discussion, the following conclusions are made:

- For all mixes, higher foam volume $\left(1300 \mathrm{~kg} / \mathrm{m}^{3}\right)$ resulted in a greater degree of void merging, leading to large irregular voids which resulted in a wide distribution of void sizes (increased D50 and D90) and lower strength.

- For a given density, although the additives in combination led to increased void numbers, higher strength was achieved due to reduced void size and connectivity, by preventing their merging and producing a narrow void size distribution (decreased $\mathrm{D}_{50}$ and $\mathrm{D}_{90}$ ).

- Adding a superplasticizer on its own resulted in a void structure fairly similar to that from all additives in combination, implying that it is the superplasticizer that has the greatest influence on voids.

- A reduction in the $\mathrm{D}_{50}$ and $\mathrm{D}_{90}$ of air voids is clearly linked to an increase in strength for each density implying that the effect of additives (both individually and in combination) was significant.

- Proportional strength increase with density is greater for the foamed concrete mixes than for comparable unfoamed concrete, apparently because a difference in their failure mechanisms due to a presence of foam in the foamed concrete.

- Not only enhancement of void structure but also improvement to cement paste microstructure of foamed concrete both contribute to strength gain.

\section{Acknowledgements}

The authors would like to acknowledge the support of the Higher Committee for Education Development in Iraq (HCED) for the research scholarship enabling this work to be conducted as part of a larger research project. The authors also wish to thank Dr Daniel Wells (E-A-B Associates Company, UK) for providing the foaming agent. Finally, the valuable help and comments of $\mathrm{Mr}$ Thomas Buss (University of Nottingham) during the microscopy observation and Mr Martin Roe (University of Nottingham) during the SEM testing are gratefully acknowledged. 
Table 1. Mix proportions of the all selected foamed concrete mixes.

\begin{tabular}{lccccccccc} 
& \multicolumn{7}{c}{ Mixes } \\
\cline { 2 - 9 } & FC3 & FCa3 & FC6 & FCs6 & FCf6 & FCp6 & FCa6 & FC9 & FCa9 \\
\hline Target density $\left(\mathbf{k g} / \mathbf{m}^{\mathbf{3}}\right)$ & 1300 & 1300 & 1600 & 1600 & 1600 & 1600 & 1600 & 1900 & 1900 \\
Cement content $\left(\mathbf{k g} / \mathbf{m}^{3}\right)$ & 500 & 450 & 500 & 450 & 500 & 500 & 450 & 500 & 450 \\
Silica Fume $\left(\mathbf{k g} / \mathbf{m}^{\mathbf{3}}\right)$ & - & 50 & - & 50 & - & - & 50 & - & 50 \\
W/b ratio* & 0.475 & 0.3 & 0.5 & 0.5 & 0.5 & 0.325 & 0.325 & 0.525 & 0.35 \\
Superplasticizer $\left(\mathbf{k g} / \mathbf{m}^{3}\right)$ & - & 7.5 & - & - & - & 7.5 & 7.5 & - & 7.5 \\
Water content $\left(\mathbf{k g} / \mathbf{m}^{\mathbf{3}}\right)$ & 237.5 & 150 & 250 & 250 & 250 & 162.5 & 162.5 & 262.5 & 175 \\
Sand content $\left(\mathbf{k g} / \mathbf{m}^{\mathbf{3}}\right)$ & 562 & 514 & 850 & 850 & 680 & 930 & 744 & 1137.5 & 974 \\
Fly Ash $\left(\mathbf{k g} / \mathbf{m}^{\mathbf{3}}\right)$ & - & 128.5 & - & - & 170 & - & 186 & - & 243.5 \\
Foam $\left(\mathbf{k g} / \mathbf{m}^{3}\right)$ & 19.4 & 19.4 & 13.3 & 13.3 & 13.3 & 13.3 & 13.3 & 7.6 & 7.6 \\
Foaming agent $\left(\mathbf{k g} / \mathbf{m}^{\mathbf{3}}\right)$ & 0.35 & 0.35 & 0.24 & 0.24 & 0.24 & 0.24 & 0.24 & 0.13 & 0.13 \\
Foam $\left(\mathbf{m}^{\mathbf{3}}\right)$ & 0.424 & 0.424 & 0.295 & 0.295 & 0.295 & 0.295 & 0.295 & 0.166 & 0.166
\end{tabular}
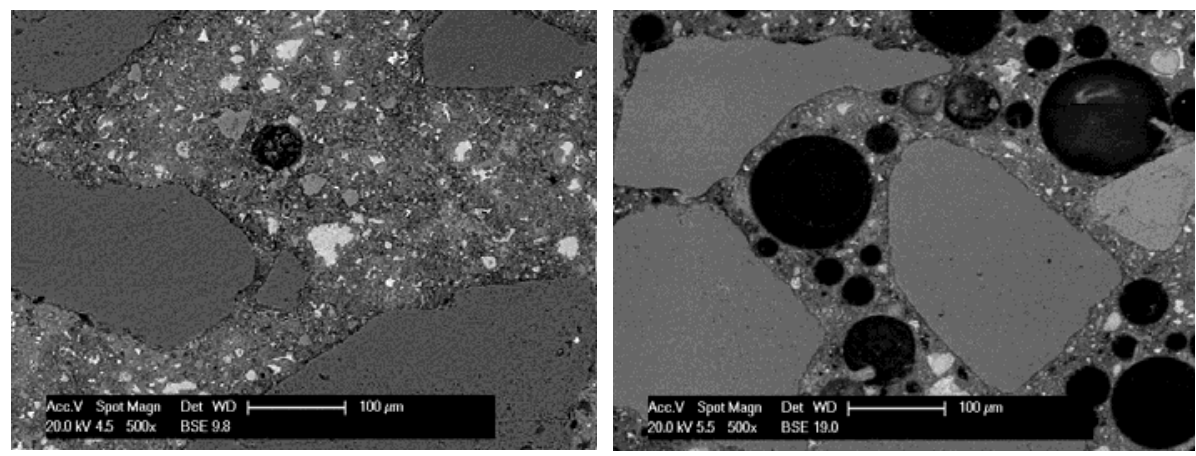

Fig. 1. SEM images for $1600 \mathrm{~kg} / \mathrm{m}^{3}$, (left) mix without foam, (right) foamed concrete mix
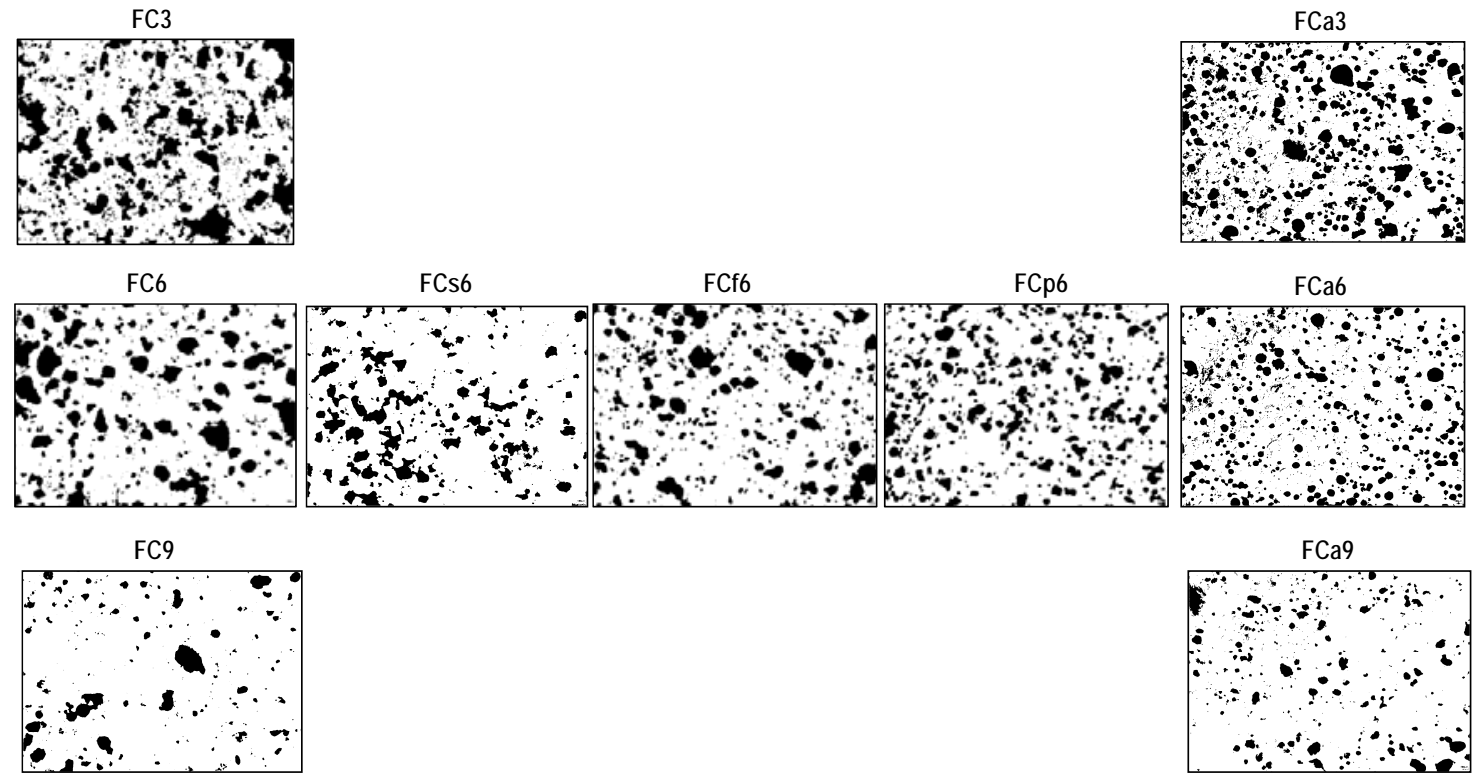

Fig. 2. Typical binary images $[15.43 \mathrm{~mm} \times 11.57 \mathrm{~mm}]$ for the selected mixes 


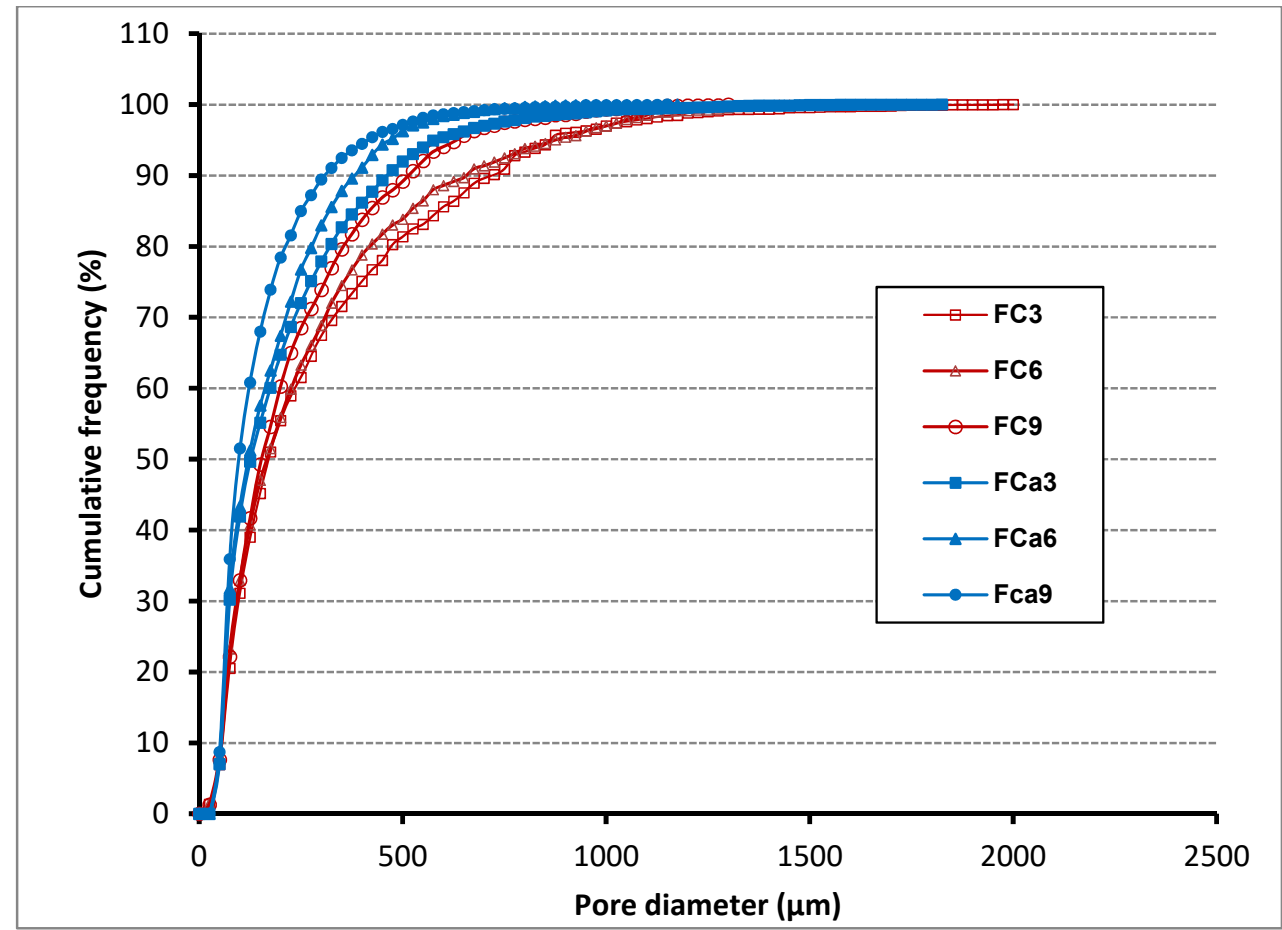

Fig. 3. Cumulative frequency (\%) of pore diameters of FC and FCa foamed concrete mixes

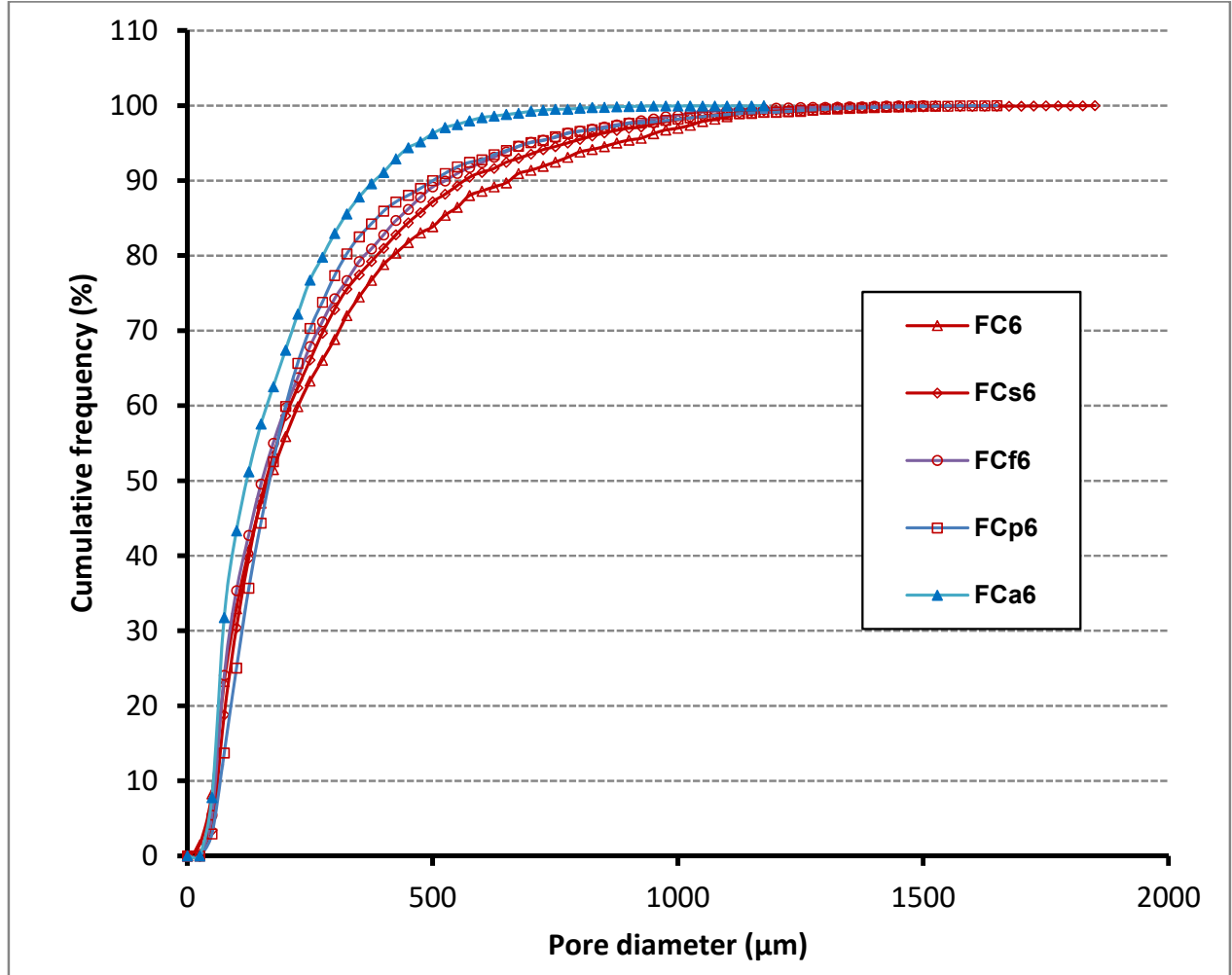

Fig. 4. Cumulative frequency (\%) of pore diameters of $1600 \mathrm{~kg} / \mathrm{m}^{3}$ mixes 
Table 2. Parameters of pores sizes and circularity of selected foamed concrete mixes

\begin{tabular}{lccccccccc}
\cline { 2 - 4 } & FC3 & FCa3 & FC6 & FCs6 & FCf6 & FCp6 & FCa6 & FC9 & FCa9 \\
\hline $\mathbf{D}_{\mathbf{5 0}}(\boldsymbol{\mu \mathrm { m } )}$ & 180 & 125 & 175 & 160 & 165 & 165 & 120 & 165 & 95 \\
\hline $\mathbf{D}_{\mathbf{9 0}}(\boldsymbol{\mu \mathrm { m }})$ & 750 & 465 & 650 & 565 & 510 & 500 & 385 & 525 & 315 \\
\hline
\end{tabular}

339
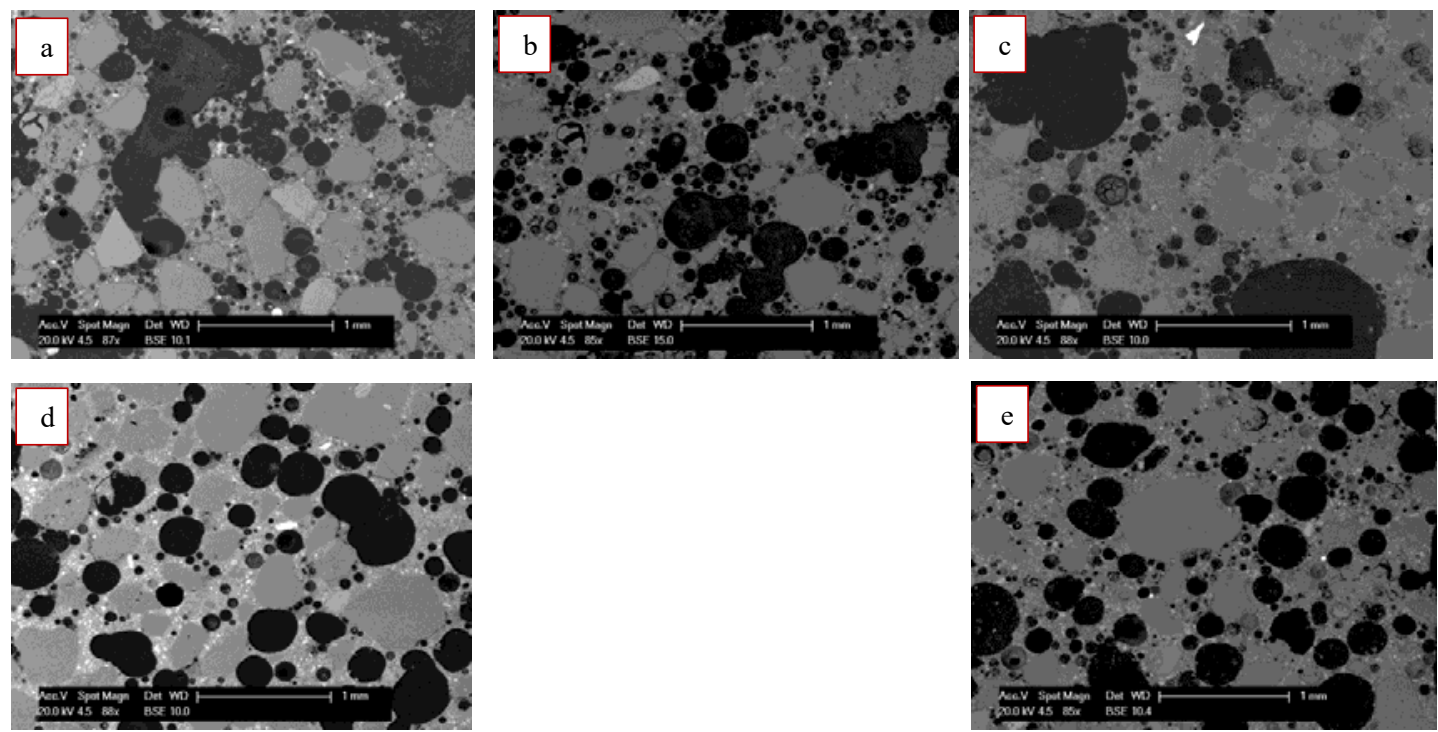

Fig. 5. SEM images for the selected $1600 \mathrm{~kg} / \mathrm{m}^{3}$ mixes (a) FC6 (b) FCs6 (c) FCf6 (d) FCp6 and (e) FCa6

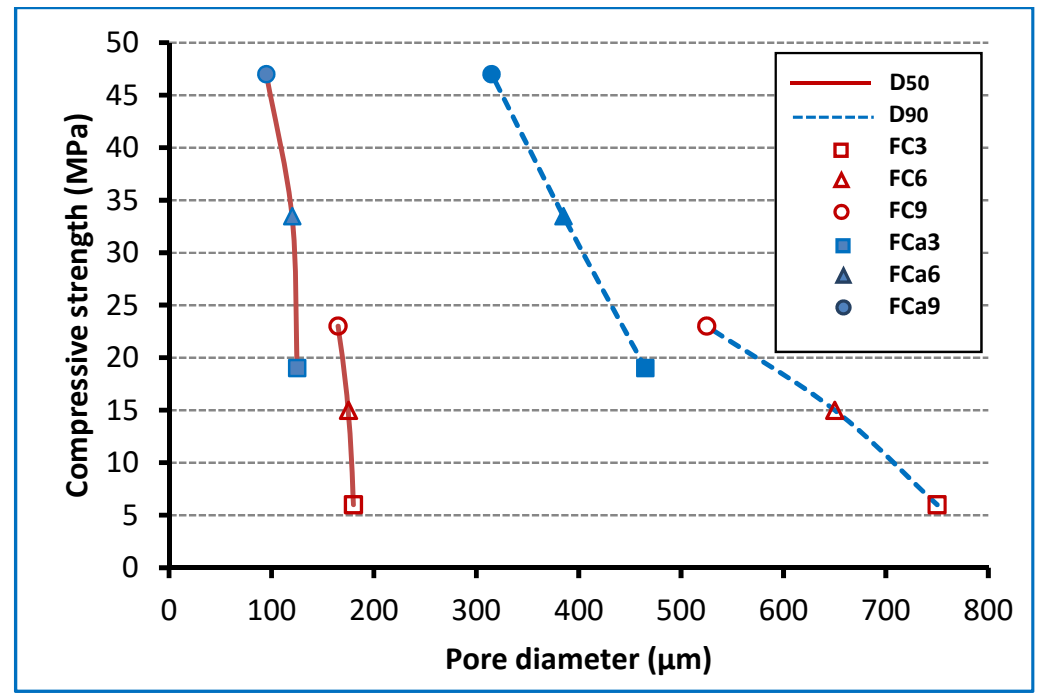

Fig. 6. Compressive strength versus void size parameters 


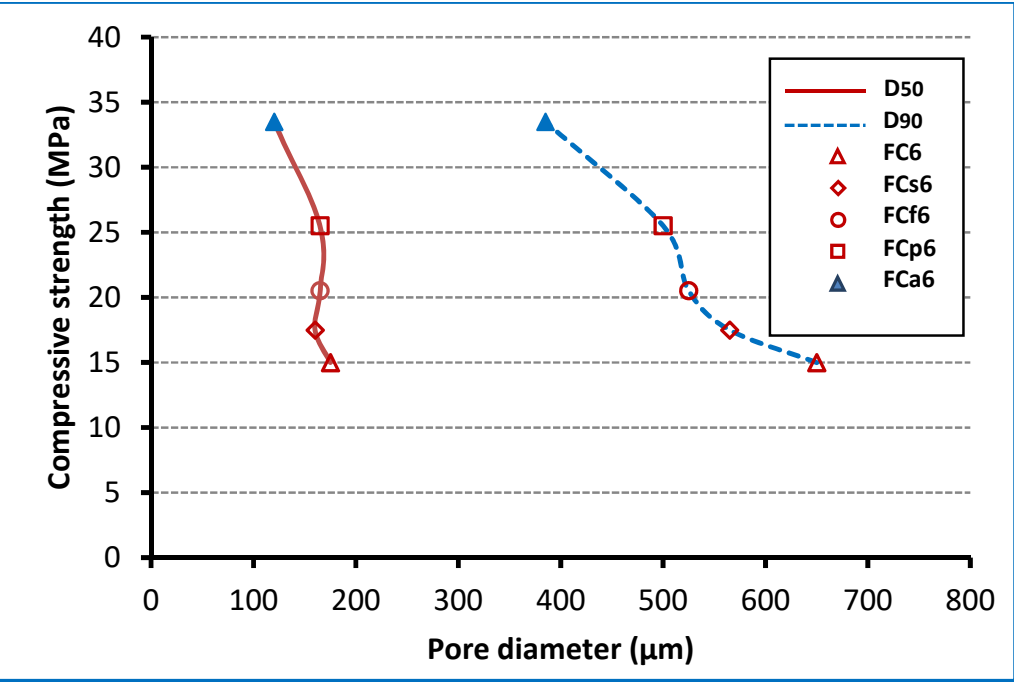

Fig. 7. Compressive strength versus void size parameters of $1600 \mathrm{~kg} / \mathrm{m}^{3}$ mixes

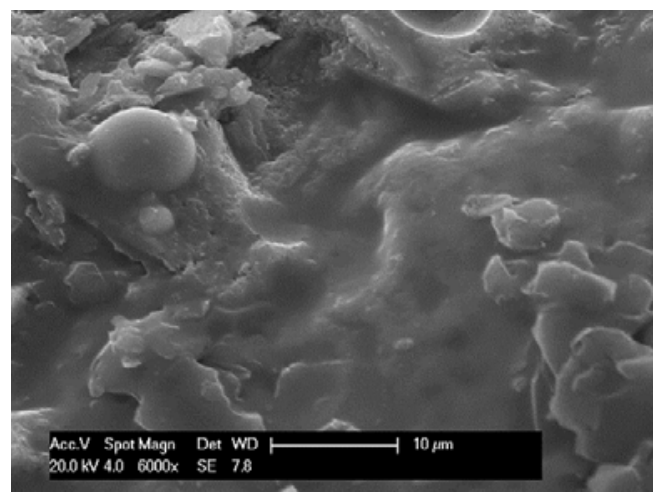

Fig. 8. Effect of additives on the cement paste microstructure, left) FC6 mix, right) FCa6 mix
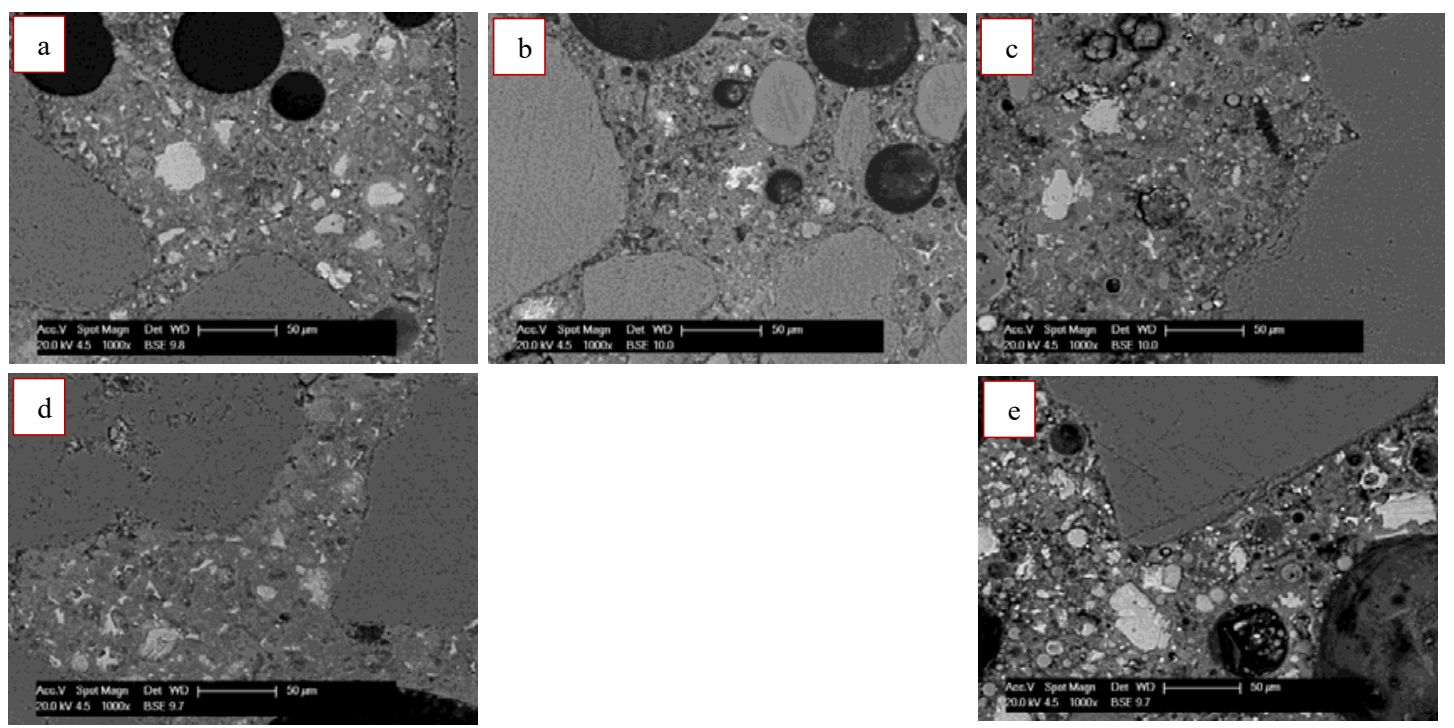

Fig. 9. Effect of additives on the cement paste microstructure a) FC6 b) FCs6 c) FCf6 d) FCp6 and e) $\mathrm{FCa} 6$ 


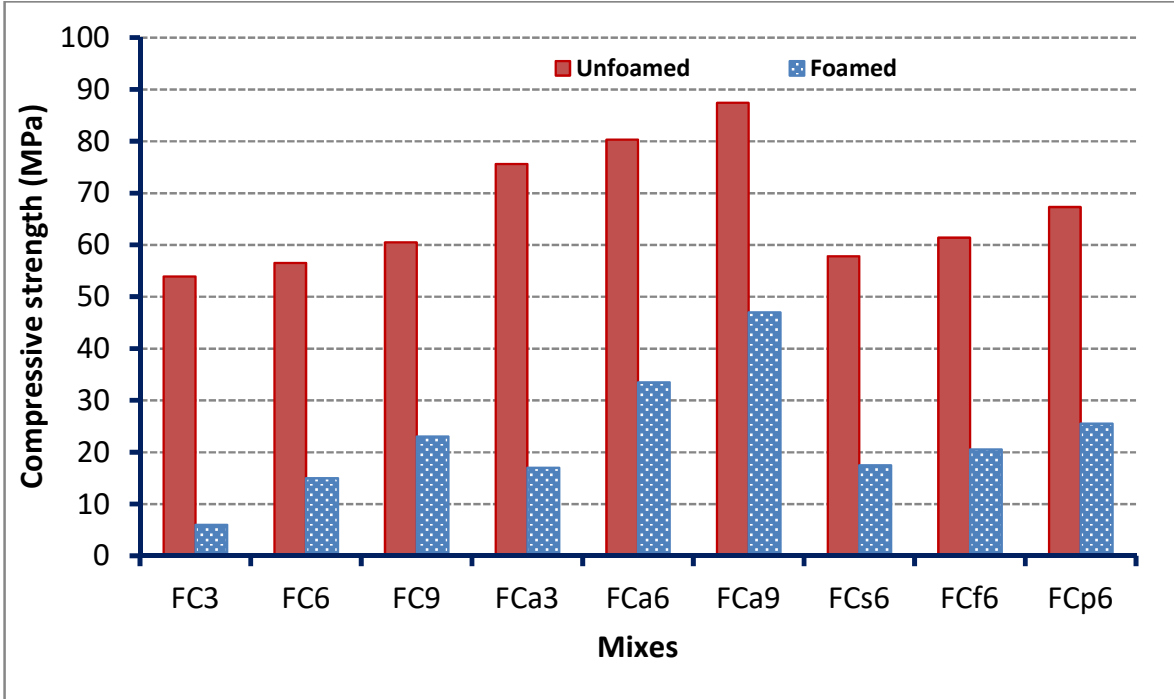

Fig. 10. 28-day Compressive strength of unfoamed and foamed concrete mixes

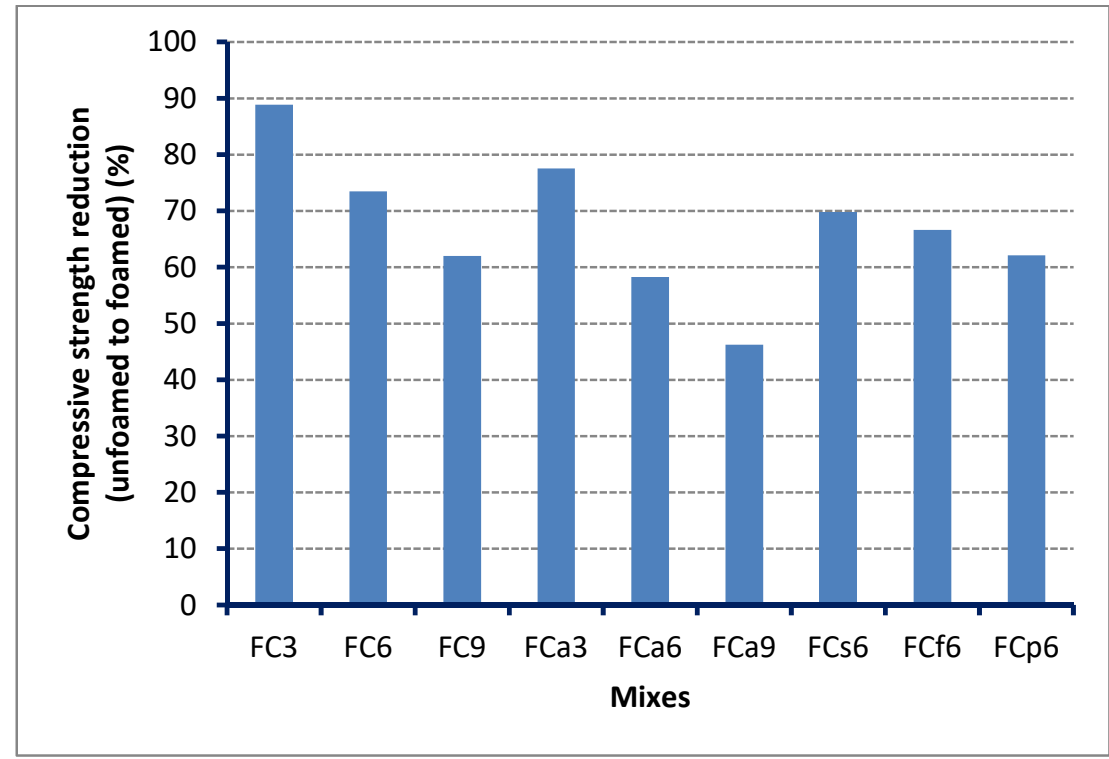

Fig. 11. Compressive strength reduction (\%) of unfoamed to foamed concrete for the same mixes 


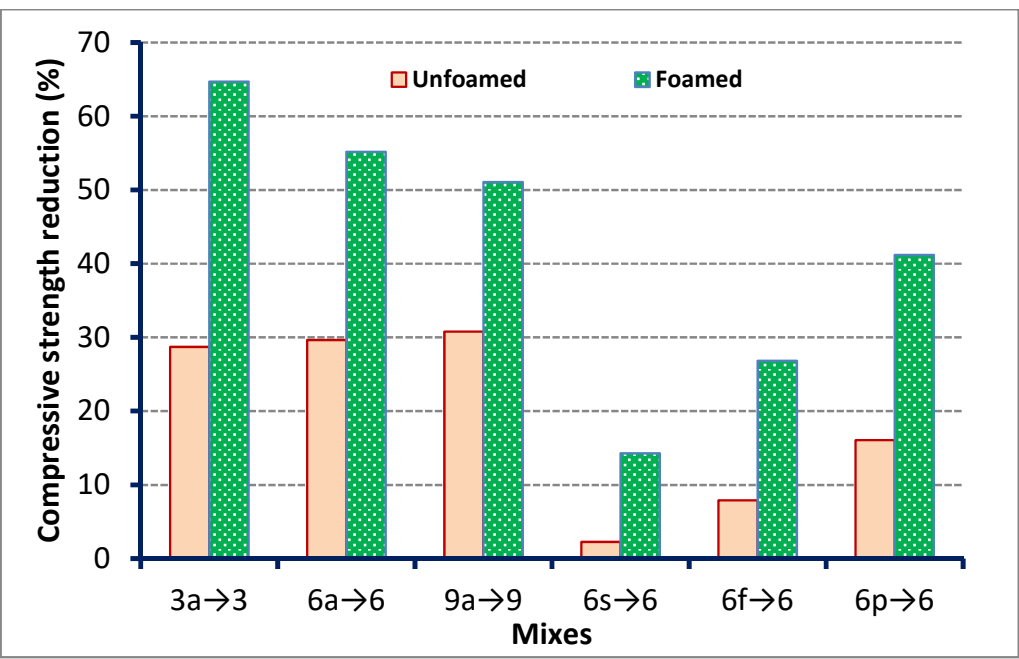

Fig. 12. Compressive strength reduction (\%) of unfoamed and foamed concrete mixes (from with additives to conventional)
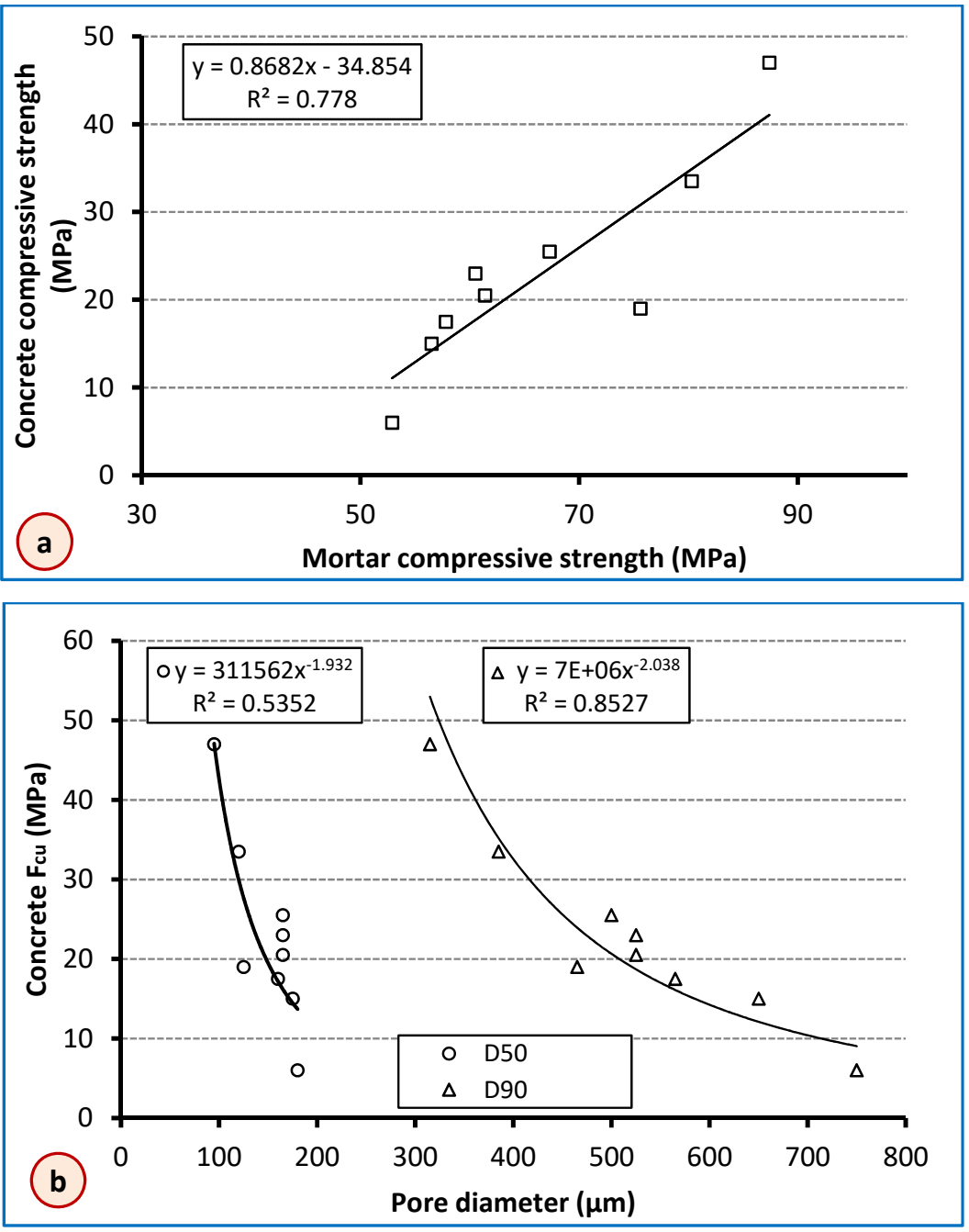

Fig. 13. (a) Mortar strength and (b) pore size parameters versus foamed concrete strength for all investigated mixes 


\section{References}

1. Narayanan, N. and K. Ramamurthy, Structure and properties of aerated concrete: a review. Cement and Concrete Composites, 2000. 22(5): p. 321-329.

2. Ramamurthy, K., E.K. Kunhanandan Nambiar, and G. Indu Siva Ranjani, A classification of studies on properties of foam concrete. Cement and Concrete Composites, 2009. 31(6): p. 388-396.

3. Nambiar, E. and K. Ramamurthy, Air-void characterisation of foam concrete. Cement and concrete research, 2007.37(2): p. 221-230.

4. Just, A. and B. Middendorf, Microstructure of high-strength foam concrete. Materials Characterization, 2009. 60(7): p. 741-748.

5. Kearsley, E., The Effect of High Volume of Ungraded Fly Ash on the Properties of Foamed Concrete, in School of Civil Engineering 1999, The University of Leeds: Leeds.

6. Hilal, A.A., N.H. Thom, and A.R. Dawson, The Use of Additives to Enhance Properties of Pre- formed Foamed Concrete. International Journal of Engineering and Technology, 2015. 7(4): p. 286-293.

7. BS EN 197-1, Cement-Part 1: Composition, Specifications and Conformity Criteria for Common Cements, in British Standards Institution, London. 2011.

8. BS 882, Specification for aggregates from natural sources for concrete. British Standards Institution, London, 1992.

9. $\quad$ BS EN 405-1, Fly ash for concrete- Part 1: Defination, specifications and conformity criteria. 2005.

10. ASTM C796, Standard test method for foaming agent for use in producing cellular concrete using preformed foam. 1997, American Society for Testing and Materials.

11. Jones, M. and A. McCarthy, Preliminary views on the potential of foamed concrete as a structural material. Magazine of concrete research, 2005. 57(1): p. 21-31.

12. BS EN 12390-3, Testing hardened concrete-Compressive strength of test specimens. British European Standards Specifications, 2002.

13. BS EN 480-11, Admixtures for concrete, mortar and grout- Test methods- Part 11: Determination of air void characteristics in hardened concrete. 2005: British Standards Institution, London.

14. Hilal, A.A., N.H. Thom, and A.R. Dawson, On entrained pore size distribution of foamed concrete. Construction and Building Materials, 2014.[In Press].

15. ASTM C457, Standard test method for Microscopical Determination of Parameters of the Air-Void System in Hardened Concrete. 1998, American Society for Testing and Materials

16. Neville, A.M., Properties of concrete. 5th ed. 2011, London Pearson Education Limited. 846.

3




\section{Figures Captions}

438 Fig. 1. SEM images for $1600 \mathrm{~kg} / \mathrm{m}^{3}$, left) mix without foam, right) foamed concrete mix

439 Fig. 2. Typical binary images $[15.43 \mathrm{~mm} \times 11.57 \mathrm{~mm}]$ for the selected mixes

440 Fig. 3. Cumulative frequency (\%) of pore diameters of FC and FCa foamed concrete mixes

441 Fig. 4 Cumulative frequency (\%) of pore diameters of $1600 \mathrm{~kg} / \mathrm{m}^{3}$ mixes

442 Fig. 5. SEM images for the selected $1600 \mathrm{~kg} / \mathrm{m}^{3}$ mixes (a) FC6 (b) FCs6 (c) FCf6 (d) FCp6 443 and (e) $\mathrm{FCa} 6$

444 Fig. 6. Compressive strength versus void size distribution parameters

445 Fig. 7. Compressive strength versus void size distribution parameters of $1600 \mathrm{~kg} / \mathrm{m}^{3}$ mixes

446 Fig. 8. Effect of additives on the cement paste microstructure (left) Mortar of FC6 mix (right)

447 Mortar of FCa6 mix

448 Fig. 9. Effect of additives on the cement paste microstructure (a) FC6 (b) FCs6 (c) FCf6 (d) $449 \quad$ FCp6 and (e) FCa6

450 Fig. 10. 28-day Compressive strength of unfoamed and foamed concrete mixes

451 Fig. 11. Compressive strength reduction (\%) of unfoamed to foamed concrete for the same 452 mixes

453 Fig. 12. Compressive strength reduction (\%) of unfoamed and foamed concrete mixes (from 454 with additives to conventional)

455 Fig. 13. (a) Mortar strength and (b) pore size parameters versus foamed concrete strength for 456 all investigated mixes 